\title{
Pazopanib for Metastatic Renal Cell Carcinoma: A Registry-based Analysis of 426 Patients
}

\author{
ALEXANDR POPRACH ${ }^{1,2^{*}}$, ONDREJ FIALA $^{3,4^{*}}$, RENATA CHLOUPKOVA $^{5}$, \\ BOHUSLAV MELICHAR $^{6}$, RADEK LAKOMY ${ }^{1,2}$, KATARINA PETRAKOVA $^{1,2}$, MILADA ZEMANOVA $^{7}$, \\ KATERINA KOPECKOVA ${ }^{8}$, ONDREJ SLABY ${ }^{1,2}$, HANA STUDENTOVA ${ }^{6}$, JINDRICH KOPECKY ${ }^{9}$, \\ IGOR KISS $^{1,2}$, JINDRICH FINEK $^{3}$, LADISLAV DUSEK ${ }^{4}$ and TOMAS BUCHLER ${ }^{10}$ \\ ${ }^{1}$ Department of Comprehensive Cancer Care, Masaryk Memorial Cancer Institute, Brno, Czech Republic; \\ ${ }^{2}$ Faculty of Medicine, Masaryk University Brno, Brno, Czech Republic; \\ ${ }^{3}$ Department of Oncology and Radiotherapeutics, \\ Faculty of Medicine and University Hospital in Pilsen, Pilsen, Czech Republic; \\ ${ }^{4}$ Biomedical Center, Faculty of Medicine in Pilsen, Charles University, Pilsen, Czech Republic; \\ ${ }^{5}$ Institute of Biostatistics and Analyses, Faculty of Medicine, Masaryk University, Brno, Czech Republic; \\ ${ }^{6}$ Department of Oncology, Palacky University Medical School and Teaching Hospital, Olomouc, Czech Republic; \\ ${ }^{7}$ Department of Oncology, First Faculty of Medicine, \\ Charles University and General University Hospital, Prague, Czech Republic; \\ ${ }^{8}$ Department of Oncology, Second Faculty of Medicine, \\ Charles University and Motol University Hospital, Prague, Czech Republic; \\ ${ }^{9}$ Department of Oncology, University Hospital in Hradec Králové, Hradec Králové, Czech Republic; \\ ${ }^{10}$ Department of Oncology, First Faculty of Medicine, \\ Charles University and Thomayer University Hospital, Prague, Czech Republic
}

\begin{abstract}
Background: Pazopanib is approved for the firstline treatment of patients with metastatic renal cell carcinoma ( $m R C C)$. The present study was a retrospective registry-based analysis of 426 patients with mRCC treated with pazopanib as first-line targeted therapy. Patients and Methods: The data were obtained from the Renal Cell Carcinoma Information system registry. Patient baseline parameters, treatment course and outcomes, and toxicity were analysed. Results: Median progression-free and overall survival were $12.9 \quad(95 \%$ confidence interval $(C I)=11.0-14.8)$ months and $33.2(95 \%$ $C I=29.9-36.4)$ months, respectively. Overall response rate and disease control rate were $25.1 \%$ and $57.4 \%$, respectively. Adverse events led to discontinuation of treatment in 37
\end{abstract}

\footnotetext{
*These Authors contributed equally to this study.

Correspondence to: Tomas Buchler, Department of Oncology, Thomayer University Hospital, Videnska 800, 14059 Prague, Czech Republic. Tel: +42 0261082637, Fax: +42 0261082522, e-mail: tomas.buchler@ftn.cz
}

Key Words: Renal cell carcinoma, pazopanib, response, survival, cancer registry.
(12.1\%) patients. Conclusion: The results confirm that pazopanib is an effective and safe first-line targeted treatment in patients with mRCC. Both the International mRCC Database Consortium and the Memorial Sloan Kettering models were valid predictors of prognosis and nephrectomy was associated with improved survival.

Pazopanib is an oral inhibitor of the tyrosine kinase domain of the vascular endothelial growth factor receptors (VEGFR) 1-3, platelet-derived growth factor receptors (PDGFR) $\alpha$ and $\beta$ and stem cell factor receptor (SCF, C$\mathrm{KIT}$ ). Based on the results of a phase III registration study, pazopanib was approved for the first-line treatment of patients with metastatic renal cell carcinoma (mRCC) (1). Another randomised phase III study compared pazopanib with sunitinib, showing similar treatment outcomes (2). Thus, both pazopanib and sunitinib are currently considered as standard first-line options for the treatment of patients with mRCC.

Although a number of observational and retrospective studies have been published exploring different aspects of sunitinib therapy in real-world clinical practice, the number of studies evaluating pazopanib is notably lower due to the shorter duration of pazopanib availability (3-21). 
The aim of this study was a retrospective analysis of patients with mRCC treated with pazopanib in the Czech Republic. The present cohort of patients is one of the largest retrospective cohorts from a single country with a homogeneous population.

\section{Patients and Methods}

Study design and data source. The present study was a retrospective registry-based analysis of adult patients with mRCC treated with pazopanib as the first-line targeted treatment who started pazopanib between August 2011 and December 2015. Patients who had received cytokine therapy prior to pazopanib were also eligible. Pazopanib was administered orally until disease progression, unacceptable toxicity, or patient refusal. Temporary discontinuation or dose reductions due to toxicity, according to clinical practice guidelines, were recorded. Subsequent anticancer therapy for patients with progressive disease was at the discretion of the treating physicians.

The data were obtained from the Renal Cell Carcinoma Information System (RENIS) registry that contains data on approximately $95 \%$ of patients with mRCC treated with targeted therapy in the Czech Republic. This registry was established in 2007, and the patient data are stored in an anonymised form and updated twice a year $(9,22,23)$. The RENIS registry provides retrospective anonymised data on patient baseline clinical characteristics, as well as on previous therapies for mRCC, laboratory parameters, treatment course and outcomes, and toxicity (http://renis.registry.cz).

The interval of tumour assessment was not pre-specified, but the reimbursement conditions for pazopanib required radiological tumour assessment at least every three cycles. Treatment response was assessed using the Response Evaluation Criteria In Solid Tumors version 1.1 (24) and toxicity using the National Cancer Institute Common Terminology Criteria for Adverse Events Version $4.0(25)$.

All procedures performed were in accordance with ethical standards and with the 1964 Helsinki declaration and its later amendments or comparable ethical standards. The RENIS registry and the use of registry data for analysis were approved by the Multicentre Ethics Committee of the University Hospital and the Masaryk Memorial Cancer Institute in Brno, Czech Republic (registration number 2007508, approval number for current version 201703S12R). All patients included in the study signed informed consent with the inclusion and subsequent analysis of their data in the registry.

Statistical analysis. Descriptive statistics and frequency tables were used to characterize the sample data set, with exception of pazopanib treatment duration, which was estimated using the Kaplan-Meier method.

Overall survival (OS) was defined as the time from pazopanib treatment initiation to the date of death due to any cause. Progression-free survival (PFS) was defined as the time from pazopanib treatment initiation to the date of first documented progression or death from any cause. PFS, OS and treatment duration were estimated using the Kaplan-Meier method, with all point estimates including $95 \%$ confidence intervals (95\% CI). Statistical significance of differences in survival among subgroups was assessed using the log-rank test. For multivariable analysis, the
Cox proportional hazards model was used with adjustment for the Memorial Sloan-Kettering Cancer Center (MSKCC) (26) or International Metastatic Renal Cell Carcinoma Database Consortium (IMDC) criteria (27). Hazard ratios were calculated with 95\% CI and supported by estimating the significance level.

Decision on statistical significance was based on a significance level of $\alpha=0.05$.

\section{Results}

Baseline characteristics. A total of 426 patients with mRCC treated with pazopanib as first targeted treatment were analyzed, with the vast majority (397 patients; $93.2 \%$ ) being treatment- naïve. Twenty-nine $(6.8 \%)$ patients had been previously treated with cytokine therapy, mostly low-dose interferon- $\alpha$. The median age of patients at pazopanib initiation was 67 years, $288(67.6 \%)$ patients were males, $407(95.5 \%)$ patients had clear cell histology, and 346 (81.2\%) had the primary tumour removed by nephrectomy or nephron-sparing surgery. The detailed baseline patient characteristics are summarised in Table I. At the time of data analysis (4 April 2017), 252 (59.2\%) patients were alive, 139 (32.6\%) had died and 35 (8.2\%) had been lost to follow-up. Treatment with pazopanib was terminated in 305 (71.6\%) patients and $121(28.4 \%)$ patients continued on treatment. Adverse events led to discontinuation of treatment in 37 patients ( $12.1 \%$ of all patients with discontinued treatment). These were classified as severe (grade 3 or 4 ) in the registry and included seven (18.9\%) cases of gastrointestinal toxicity, six $(16.2 \%)$ of metabolic toxicity, five $(13.5 \%)$ of cardiovascular toxicity, two $(5.4 \%)$ of neurological toxicity, and one $(2.7 \%)$ case each of respiratory and skin toxicity. Other or not otherwise specified severe toxicity leading to treatment discontinuation was reported in 15 patients $(40.5 \%)$. No cases of toxicity-related death were reported.

Treatment outcomes. Median PFS and OS for the whole cohort were 12.9 (95\% CI=11.0-14.8) months and 33.2 (95\% $\mathrm{CI}=29.9-36.4)$ months, respectively. One- and two-year OS probability was $83.3 \%$ (95\% CI=79.4-87.2\%) and $63.0 \%$ (95\% CI=57.2-68.8\%), respectively. Complete response, partial response (PR) and stable disease (SD) were observed in six (1.4\%), $101(23.7 \%)$ and $144(33.8 \%)$ patients, respectively. Overall response rate and disease control rate were $25.1 \%$ and $58.9 \%$, respectively. Median treatment duration was $9.6(95 \% \mathrm{CI}=8.3-10.9)$ months. Treatment response, PFS and OS data are summarised in Table II.

Survival in selected patient subgroups. Application of MSKCC and IMDC prognostic stratification systems to the present data resulted in marked separation of the survival curves, confirming the validity for patients treated with pazopanib. PFS and OS data according to MSKCC and IMDC risk groups are summarized in Table III. 
Table I. Baseline patient characteristics.

\begin{tabular}{lc}
\hline Characteristic & $\mathrm{n}=426$ \\
\hline Gender, $\mathrm{n}(\%)$ & \\
Male & $288(67.6)$ \\
Female & $138(32.4)$ \\
Median age at diagnosis (range), years & $64(37-85)$ \\
Histology, $\mathrm{n}(\%)$ & \\
Clear cell carcinoma & $407(95.5)$ \\
Other & $19(4.5)$ \\
Stage at diagnosis, n (\%) & \\
Stage I & $61(14.3)$ \\
Stage II & $50(11.7)$ \\
Stage III & $77(18.1)$ \\
Stage IV & $185(43.4)$ \\
Unknown & $53(12.4)$ \\
Fuhrman grade, $\mathrm{n}(\%)$ & \\
G1 well-differentiated & $35(8.2)$ \\
G2 moderately differentiated & $156(36.6)$ \\
G3-4 poorly differentiated / non-differentiated & $154(36.2)$ \\
Not assessed & $81(19.0)$ \\
Prior nephrectomy, $\mathrm{n}(\%)$ & $346(81.2)$ \\
Prior cytokine therapy, $\mathrm{n}(\%)$ & $29(6.8)$ \\
Median age at pazopanib initiation (range), years & $67(37-88)$ \\
ECOG PS at pazopanib treatment initiation, n (\%) & \\
PS 0 & $160(37.6)$ \\
PS 1 & $251(58.9)$ \\
PS 2 or PS 3 & $14(3.3)$ \\
Unknown & $1(0.2)$ \\
MSKCC risk group ${ }^{2}$ & \\
Good prognosis & $207(48.6)$ \\
Intermediate prognosis & $131(30.8)$ \\
Poor prognosis & $275(64.6)$ \\
Unknown & $17(4.0)$ \\
IMDC risk group ${ }^{2}$ & $3(0.7)$ \\
Good prognosis & \\
Intermediate prognosis & $64(15.0)$ \\
Poor prognosis & $134(31.5)$ \\
Unknown & \\
\hline
\end{tabular}

ECOG PS, Eastern Cooperative Oncology Group Performance Status; MSKCC, Memorial Sloan-Kettering Cancer Center; IMDC, International Metastatic Renal-Cell Carcinoma Database Consortium ${ }^{1}$ MSKCC score was evaluable in 423 patients; ${ }^{2}$ IMDC score was evaluable in 219 patients.

The analysis of the results according to the Fuhrman grade showed no significant correlation with PFS or OS after adjustments for MSKCC and IMDC score.

Median PFS and OS were significantly superior in patients who had undergone prior cytoreductive nephrectomy. There were 185 patients with metastatic disease at diagnosis. Median PFS was 11.5 (95\% CI=7.6-15.4) months versus 8.5 (95\% CI 5.8-11.1) months and median OS 31.4 (95\% CI=24.7-38.1) months versus 15.3 (95\% CI=9.8-20.9) months $(p=0.002)$ for patients who had undergone cytoreductive nephrectomy $(\mathrm{n}=114)$ versus those who had not $(\mathrm{n}=71)$, respectively (Figure 1).
Table II. Objective treatment response, progression-free (PFS) and overall survival (OS)

\begin{tabular}{lc}
\hline & $\mathrm{n}=426$ \\
\hline Best treatment response, $\mathrm{n}(\%)$ & \\
CR & $6(1.4)$ \\
PR & $101(23.7)$ \\
SD & $144(33.8)$ \\
PD & $79(18.5)$ \\
Not evaluated & $96(22.5)$ \\
ORR & $107(25.1)$ \\
DCR & $251(58.9)$ \\
Median PFS (95\% CI) & 12.9 months $(11.0-14.8)$ \\
6-Month & $76.5 \%(72.3-80.7 \%)$ \\
1-Year & $53.2 \%(48.0-58.4 \%)$ \\
2-Year & $27.3 \%(22.0-32.6 \%)$ \\
Median OS (95\% CI) & 33.2 months $(29.9-36.4)$ \\
6-Month & $92.5 \%(89.9-95.1 \%)$ \\
1-Year & $83.3 \%(79.4-87.2 \%)$ \\
2-Year & $63.0 \%(57.2-68.8 \%)$ \\
\hline
\end{tabular}

$\mathrm{CR}$, Complete response; PR, partial response; SD, stable disease; PD, progressive disease; ORR, overall response rate; DCR, disease control rate; $\mathrm{CI}$, confidence interval.

There was no statistically significant difference in PFS or OS between patients achieving PR and those with SD as the best response. Evaluating only the 305 patients with terminated pazopanib treatment, there were 63 patients with PR and 108 patients with SD as the achieved best response. Median PFS was 12.1 (95\% CI=10.6-13.6) months versus $12.6(95 \% \mathrm{CI}=10.1-15.0)$ months $(p=0.574)$ and median OS 24.7 (95\% CI=17.8-31.6) months versus 30.9 (95\% CI=25.2$36.5)$ months $(p=0.077)$ respectively (Figure 2$)$. The overall number of treatment lines and subsequent treatments administered were similar for these subgroups.

\section{Discussion}

The present analysis describes the results of pazopanib therapy in real-life clinical practice. Although prospective randomized clinical trials represent an obvious standard for the evaluation of efficacy of new anticancer agents, it is not always easy to extrapolate the results into real-world clinical practice as a significant proportion of patients seen in the clinic would not be eligible for enrolment into clinical trials.

The results of this retrospective registry-based study confirm that pazopanib is an effective option for first-line targeted treatment of patients with mRCC, with the median PFS and OS reaching 12.9 and 33.2 months, respectively. Both MSKCC and IMDC scoring systems performed well in the present cohort and the results suggest that the outcomes are similar to prior reported data across all three defined prognostic groups. Moreover, these findings are consistent 
Table III. Progression-free and overall survival according to Memorial Sloan-Kettering Cancer Center (MSKCC) and International Metastatic Renal-Cell Carcinoma Database Consortium (IMDC) score (number of evaluable patients 423 and 219, respectively).

\begin{tabular}{|c|c|c|c|c|c|c|}
\hline \multirow[t]{2}{*}{ Score } & \multirow[t]{2}{*}{ Prognosis } & \multirow[t]{2}{*}{$\mathrm{n}$} & \multicolumn{2}{|c|}{ Progression-free survival } & \multicolumn{2}{|c|}{ Overall survival } \\
\hline & & & Median (95\% CI), months & $p$-Value* & Median (95\% CI), months & $p$-Value* \\
\hline \multirow[t]{3}{*}{ MSKCC } & Good & 131 & $20.0(15.0-25.1)$ & \multirow[t]{3}{*}{$<0.001$} & Not reached & \multirow[t]{3}{*}{$<0.001$} \\
\hline & Intermediate & 275 & $11.3(9.6-12.9)$ & & $28.5(24.0-32.9)$ & \\
\hline & Poor & 17 & $7.4(5.2-9.6)$ & & $15.1(5.0-25.3)$ & \\
\hline \multirow[t]{3}{*}{ IMDC } & Good & 64 & $21.4(10.3-32.5)$ & \multirow[t]{3}{*}{$<0.001$} & Not reached & \multirow[t]{3}{*}{$<0.001$} \\
\hline & Intermediate & 134 & $12.3(8.2-16.5)$ & & $31.4(23.4-39.3)$ & \\
\hline & Poor & 21 & $5.9(1.1-10.7)$ & & $9.2(3.2-15.1)$ & \\
\hline
\end{tabular}

CI, Confidence interval. * Log-rank test.

with a report using data from the same registry evaluating the MSKCC and IMDC scoring systems in patients with mRCC treated with sunitinib (23).

Median PFS and OS for the overall study population treated with pazopanib in the registration phase III clinical trial reported by Sternberg et al. was 9.2 and 22.9 months, respectively, while the median PFS and OS for the treatmentnaïve population was 11.1 and 22.9 months, respectively. SD was observed in $38 \%$ of patients and PR in $30 \%$ of patients treated with pazopanib (1). In the COMPARZ trial, the median PFS and OS for patients treated with pazopanib were 8.4 and 28.4 months, respectively. There was no statistically significant difference in PFS and OS between agents (2).

In addition to randomised trials, several retrospective observational studies evaluating the efficacy of pazopanib have been reported, but most included a limited number of patients. The largest retrospective study analysed the IMDC data and included 919 patients treated with pazopanib and 6,519 patients treated with sunitinib (17). The study showed similar efficacy of both agents in the first-line treatment of mRCC. The median PFS and OS for patients treated with pazopanib were 8.4 and 22.6 months, respectively, while the overall response rate was $28 \%$. Several other relatively small retrospective studies focusing on the efficacy of first-line pazopanib in real-world clinical practice were recently published, including reports by Matrana et al. (88 patients) (18), Galvis et al. (104 patients) (19), Vogelzang et al. (177 patients) (20) and Perez-Valderrama et al. (278 patients) (21). When comparing the present results with those obtained from the phase III clinical trials mentioned above, longer PFS and OS for the whole patient cohort was observed. This difference might be explained by a different baseline characteristics of patients included in the various studies. In the present study, there was a markedly lower proportion of patients with brain metastases, non-clear cell histology,Eastern Cooperative Oncology Group performance status $\geq 2$ or poor prognosis according to MSKCC/IMDC scoring system as a consequence of the reimbursement criteria in the Czech Republic that preclude treatment with pazopanib in these patient subgroups.

The impact of tumour grade on outcome has been recently suggested by Chrom et al., who reported Fuhrman grade as being an independent prognostic factor for patients with mRCC treated with first-line tyrosine-kinase inhibitors (28). In the present study, we did not confirm these results, suggesting that the impact of Fuhrman grade is sufficiently contained in the currently used prognostic models. Although we observed longer OS for patients with Fuhrman grade 1-2 compared to those with grade 3-4, there was no significant correlation when the data were adjusted for prognostic factors included in the MSKCC and IMDC scoring systems.

We observed significantly longer PFS and OS for patients who had undergone cytoreductive surgery including nephrectomy or nephron-sparing surgery in the presence of metastatic disease before the initiation of pazopanib treatment. However, clear evidence of the benefit of cytoreductive surgery followed by targeted therapy in the metastatic setting is lacking, although nonrandomised data suggest a possible survival advantage for this approach (29). Recently, a large metaanalysis including 39,953 patients was conducted by Petrelli $e t$ al., with the results indicating markedly reduced risk of death in patients who had undergone prior cytoreductive surgery compared with those treated with targeted therapies alone (30), which is consistent with the results of the present study.

OS of patients with $\mathrm{mRCC}$ is significantly influenced by second-line therapies. There is emerging evidence that VEGFR inhibitors should be continued as the second-line treatment in patients with mRCC (31). One of the novel options of second-line therapy is cabozantinib a novel inhibitor of VEGFR as well as of the AXL receptor tyrosine kinase and c-MET receptor tyrosine kinase (32). The latter two kinases are mediators of epithelial-mesenchymal transition, an important mechanism of mRCC progression after treatment with VEGFR inhibitors (33). Nivolumab, an 
A

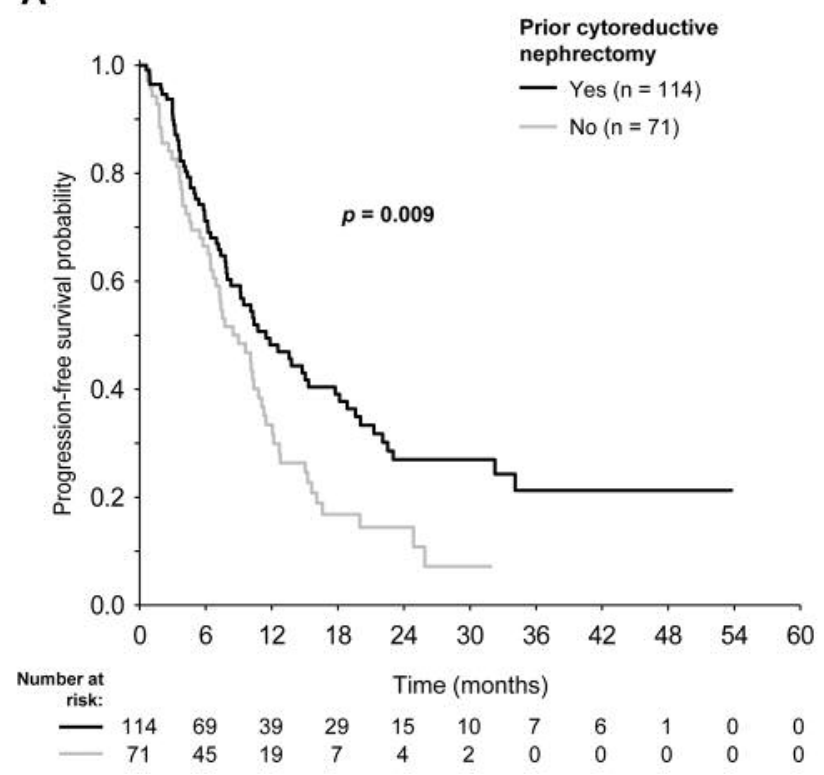

B

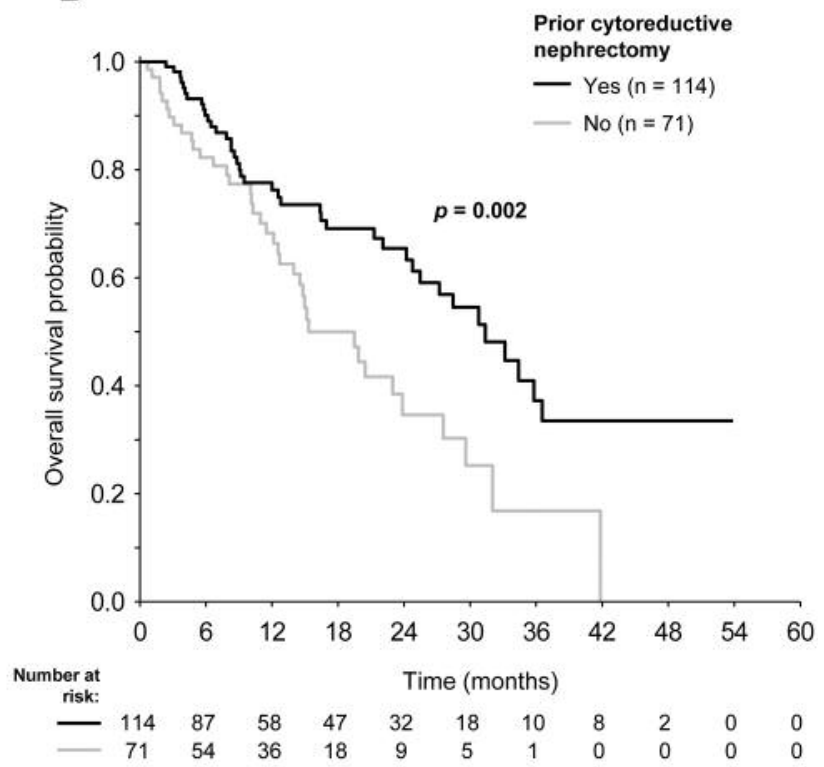

Figure 1. Progression-free (A) and overall (B) survival according to prior cytoreductive surgery (patients with synchronous metastatic disease only, $n=185$ ).

A

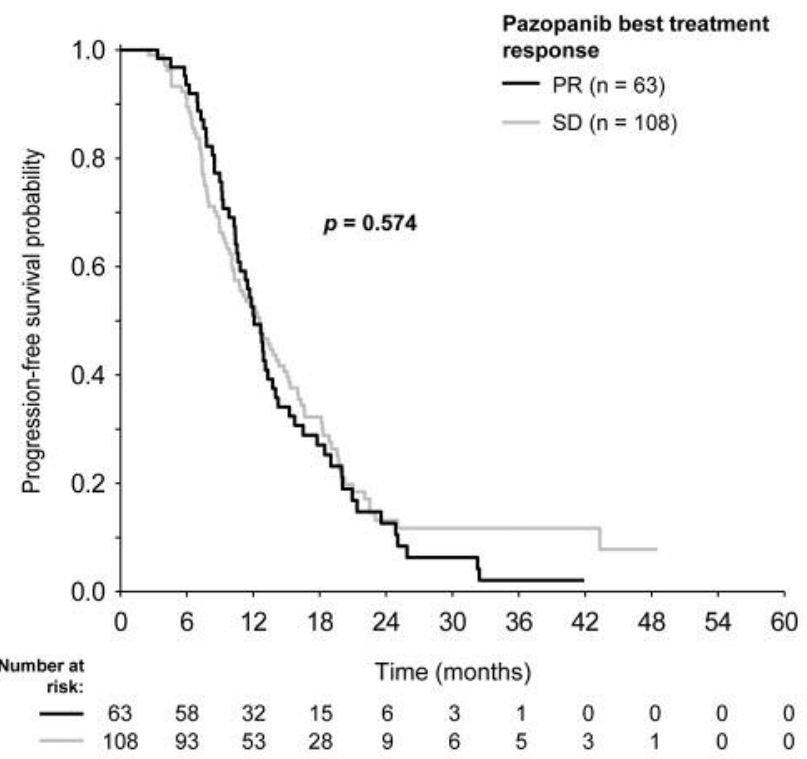

B

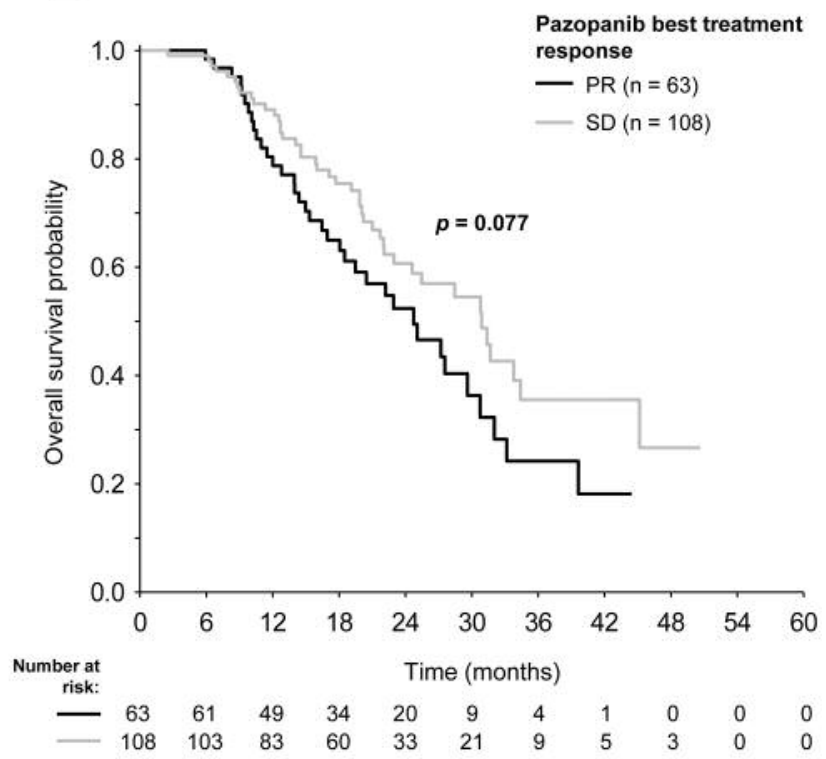

Figure 2. Progression-free (A) and overall (B) survival according to best treatment response in patients with partial remission (PR) or stable disease $(S D)(n=171)$.

inhibitor of the programmed death (PD)-1 receptor has also been recently approved for patients with progression on VEGFR inhibitors, including pazopanib (34). However, predictors for optimal sequencing of the available drugs in
mRCC are still lacking and novel prognostic markers are urgently needed (35).

The strength of the present study is the large cohort of patients treated with first-line pazopanib under conditions of 
real-life clinical practice. The principal limitations include the retrospective design, which necessarily introduced some selection bias, along with the reimbursement criteria, which led to the exclusion of patients with unfavourable prognosis. On the other hand, a number of clinical trials were conducted at the same time in the Czech Republic that included dozens of patients, introducing further complexity into the considerations of selection bias. Information on prognostic parameters was missing in some patients, specifically for the IMDC score. Possible under-reporting of adverse drug reactions in the RENIS registry represents a further limitation. Comparison with the outcome of patients from the RENIS registry treated with first-line sunitinib was not performed because these populations were not comparable.

In conclusion, the results of the present study of a large cohort of 426 patients with mRCC from real-world clinical practice confirmed that pazopanib is an effective and safe first-line targeted treatment in this population.

\section{Funding}

The project was supported by the Ministry of Health of the Czech Republic NT/13547-4/2012, AZV NV15-34678A, CEITEC-Central European Institute of Technology (CZ.1.05/1.1.00/02.0068), the MZCR-RVO (MOU, 00209805) Project, and The Ministry of Education, Youth and Sports through the BBMRI CZ (LM2010004) Project and National Sustainability Program I (NPU I) Nr. LO1503.

\section{Conflicts of Interest}

Alexandr Poprach, Radek Lakomy and Tomas Buchler received lecture honoraria from Novartis, Pfizer, Bayer-Schering, Astellas and Roche. Tomas Buchler also received research support from Roche and Novartis. Ondrej Fiala received honoraria from Roche and GSK for consultations and lectures. Bohuslav Melichar received honoraria for lectures and advisory boards from Novartis, Pfizer, Bayer-Schering, Astellas and Roche.

Authors Renata Chloupkova, Katarina Petrakova, Milada Zemanova, Katerina Kopeckova, Ondrej Slaby, Hana Studentova, Jindrich Kopecký, Igor Kiss, Jindrich Finek, and Ladislav Dusek declare no conflict of interest.

\section{Acknowledgements}

The Authors would like to thank the following Heads of the Comprehensive Cancer Centres for the permission to use data of patients from their respective regional networks: Dr Martina Chodacka, Chomutov Hospital and Masaryk Hospital in Usti nad Labem; Dr Vaclav Janovsky, Ceske Budejovice Hospital; Dr Otakar Bednarik, University Hospital, Brno; Dr Jana Prausova, Motol University Hospital, Prague; Dr David Feltl, University Hospital, Ostrava; Professor Jiri Petera, University Hospital, Hradec Kralove; Dr Lubomir Slavicek, Jihlava Hospital; Dr Jana Katolicka, St Anna University Hospital, Brno; Professor Rostislav Vyzula, Masaryk Memorial Institute of Oncology, Brno; Dr Jiri Bartos, County Hospital, Liberec; Dr Martin Safanda, Na Homolce Hospital, Prague; Dr Renata Soumarova, Novy Jicin Hospital; Professor Jitka
Abrahamova, Thomayer Hospital, Prague; Professor Lubos Petruzelka, General University Hospital, Prague; Dr Milan Kohoutek, T Bata Memorial Hospital, Zlin. The Authors are also indebted to all physicians who provided data for the RENIS registry.

\section{References}

1 Sternberg CN, Hawkins RE, Wagstaff J, Salman P, Mardiak J, Barrios CH, Zarba JJ, Gladkov OA, Lee E, Szczylik C, McCann L, Rubin SD, Chen M and Davis ID: A randomised, doubleblind phase III study of pazopanib in patients with advanced and/or metastatic renal cell carcinoma: final overall survival results and safety update. Eur J Cancer 49: 287-296, 2013.

2 Motzer RJ, Hutson TE, Cella D, Reeves J, Hawkins R, Guo J, Nathan P, Staehler M, de Souza P, Merchan JR, Boleti E, Fife $\mathrm{K}$, Jin J, Jones R, Uemura H, De Giorgi U, Harmenberg U, Wang J, Sternberg CN, Deen K, McCann L, Hackshaw MD, Crescenzo R, Pandite LN and Choueiri TK: Pazopanib versus sunitinib in metastatic renal-cell carcinoma. N Engl J Med 369: 722-731, 2013.

3 Heng DY, Chi KN, Murray N, Jin T, Garcia JA, Bukowski RM, Rini BI and Kollmannsberger C: A population-based study evaluating the impact of sunitinib on overall survival in the treatment of patients with metastatic renal cell cancer. Cancer 115: 776-783, 2009.

4 Gore ME, Szczylik C, Porta C, Bracarda S, Bjarnason GA, Oudard S, Hariharan S, Lee SH, Haanen J, Castellano D, Vrdoljak E, Schöffski P, Mainwaring P, Nieto A, Yuan J and Bukowski R: Safety and efficacy of sunitinib for metastatic renal-cell carcinoma: an expanded-access trial. Lancet 10: 757763, 2009.

5 Ansari J, Fatima A, Fernando K, Collins S, James ND and Porfiri E: Sunitinib in patients with metastatic renal cell carcinoma: Birmingham experience. Oncol Rep 24: 507-510, 2010.

6 Hwang E, Lee HJ, Sul CK and Lim JS: Efficacy and safety of sunitinib on metastatic renal cell carcinoma: a single-institution experience. Korean J Urol 51: 450-455, 2010.

7 Yuasa T, Tsuchiya N, Urakami S, Horikawa Y, Narita S, Inoue T, Saito M, Yamamoto S, Yonese J, Fukui I, Nakano K, Takahashi S, Hatake K and Habuchi T: Clinical efficacy and prognostic factors for overall survival in Japanese patients with metastatic renal cell cancer treated with sunitinib. BJU Int 109: 1349-1354, 2012.

8 Li XS, Wu X, Zhao PJ, Huang LH, Song Y, Gong K, Shen C, Yu W, Song G, Zhao Z, Zhang Z, Zhang Q, Wang G, He ZS, Zhou LQ and Jin J: Efficacy and safety of sunitinib in the treatment of metastatic renal cell carcinoma. Chin Med J 124: 2920-2924, 2011.

9 Poprach A, Bortlíček Z, Büchler T, Melichar B, Lakomý R, Vyzula R, Brabec P, Svoboda M, Dušek L and Gregor J: Patients with advanced and metastatic renal cell carcinoma treated with targeted therapy in the Czech Republic: twenty cancer centres, six agents, one database. Med Oncol 29: 3314-3320, 2012.

10 Ambring A, Björholt I, Lesén E, Stierner U and Odén A: Treatment with sorafenib and sunitinib in renal cell cancer: a Swedish register-based study. Med Oncol 30: 331, 2013.

11 Krishna VM, Noronha V, Prabhash K, Joshi A, Patil V, Bhosale B, Ravi T, Menon H, Gupta S, Banavali SD, Bakshi G and Tangaonkar HB: Sunitinib in metastatic renal cell carcimoma: a single-center experience. Indian J Cancer 50: 268-273, 2013. 
12 Yildiz I, Ekenel M, Akman T, Kocar M, Uysal M, Kanitez M, Varol U, Bayoglu IV, Tural D, Kaplan MA, Avci N, Sürmeli Z, Dede I, Ulaş A, Yazici O and Basaran M: Sunitinib for patients with metastatic non-clear cell renal cell carcinoma: a Multicenter Retrospective Turkish Oncology Group trial. Anticancer Res 34: 4329-4334, 2014

13 Patel KB, Panchal HP, Karanwal AB, Parekh BB, Shah S and Prasad S: Sunitinib in metastatic renal cell carcinoma: Experience from single-center study, efficacy and safety. Indian J Cancer 53: 118-122, 2016.

14 Joshi A, Agarwala V, Ramaswamy A, Noronha V, Patil VM, Menon S, Popat P, Sable N and Prabhash K: Initial experience with first-line pazopanib in the treatment of metastatic renal cell carcinoma: A single-institution data. Indian J Cancer 53: 575578, 2016.

15 Cecere SC, Rossetti S, Cavaliere C, Della Pepa C, Di Napoli M, Crispo A, Iovane G, Piscitelli R, Sorrentino D, Ciliberto G, Maiolino $\mathrm{P}$, Muto $\mathrm{P}$, Perdonà S, Berretta M, Pignata S, Facchini $\mathrm{G}$ and D'Aniello C: Pazopanib in metastatic renal cancer: a "real-world" experience at National Cancer Institute "Fondazione G: Pascale". Front Pharmacol 7: 287, 2016.

16 Kim MJ, Park SH, Lee JL, Lee SH, Lee SJ and Lim HY: A Korean multi-center, real-world, retrospective study of first-line pazopanib in unselected patients with metastatic renal clear-cell carcinoma. BMC Urol 16: 46, 2016.

17 Ruiz-Morales JM, Swierkowski M, Wells JC, Fraccon AP, Pasini F, Donskov F, Bjarnason GA, Lee JL, Sim HW, Sliwczynsk A, Ptak-Chmielewska A, Teter Z, Beuselinck B, Wood LA, Yuasa T, Pezaro C, Rini BI, Szczylik C, Choueiri TK and Heng DY: First-line sunitinib versus pazopanib in metastatic renal cell carcinoma: Results from the International Metastatic Renal Cell Carcinoma Database Consortium. Eur J Cancer 65: 102-108, 2016.

18 Matrana MR, Bathala T, Campbell MT, Duran C, Shetty A, Teegavarapu P, Kalra S, Xiao L, Atkinson B, Corn P, Jonasch E and Tannir NM: Outcomes of unselected patients with metastatic clear-cell renal cell carcinoma treated with first-line pazopanib therapy followed by vascular endothelial growth factor receptor tyrosine kinase inhibitors or mammalian target of rapamycin inhibitors: a single institution experience. BJU Int 118: 264-271, 2016.

19 Galvis V, Chow S, Lawrence D and Hawkins R: Clinical practice outcomes of patients treated with pazopanib for metastatic renal cell cancer $(\mathrm{mRCC})-6$ year experience at a referral centre in Manchester, UK. Eur J Cancer 49(Suppl 2): abstr. 2763, 2013.

20 Vogelzang NJ, Hackshaw MD, Hutson TE, Bhowmik D, Yap M, Rembert D and Jonasch E: First-Line and sequential use of pazopanib followed by mammalian target of rapamycin inhibitor therapy among patients with advanced renal cell carcinoma in a US community oncology setting. Clin Genitourin Cancer 13: 210-217, 2015.

21 Pérez-Valderrama B, Arranz Arija JA, Rodríguez Sánchez A, Pinto Marín A, Borrega García P, Castellano Gaunas DE, Rubio Romero G, Maximiano Alonso C, Villa Guzmán JC, Puertas Álvarez JL, Chirivella González I, Méndez Vidal MJ, Juan Fita MJ, León-Mateos L, Lázaro Quintela M, García Domínguez R, Jurado García JM, Vélez de Mendizábal E, Lambea Sorrosal JJ, García Carbonero I, González del Alba A, Suárez Rodríguez C, Jiménez Gallego P, Meana García JA, García Marrero RD, Gajate Borau P, Santander Lobera C, Molins Palau C, López
Brea M, Fernández Parra EM, Reig Torras O, Basterretxea Badiola L, Vázquez Estévez $\mathrm{S}$ and González Larriba JL: Validation of the International Metastatic Renal-Cell Carcinoma Database Consortium (IMDC) prognostic model for first-line pazopanib in metastatic renal carcinoma: the Spanish Oncologic Genitourinary Group (SOGUG) SPAZO study. Ann Oncol 27: 706-711, 2016.

22 Buchler T, Klapka R, Melichar B, Brabec P, Dusek L, Vyzula R and Abrahamova J: Sunitinib followed by sorafenib or vice versa for metastatic renal cell carcinoma - data from the Czech Registry. Ann Oncol 23: 395-401, 2012.

23 Kubackova K, Melichar B, Bortlicek Z, Pavlik T, Poprach A, Svoboda M, Lakomy R, Vyzula R, Kiss I, Dusek L, Prausova J and Buchler T: Comparison of two prognostic models in patients with metastatic renal cancer treated with sunitinib: a retrospective, registry-based study. Target Oncol 10: 557-563, 2015.

24 Eisenhauer EA, Therasse P, Bogaerts J, Schwartz LH, Sargent D, Ford R, Dancey J, Arbuck S, Gwyther S, Mooney M, Rubinstein L, Shankar L, Dodd L, Kaplan R, Lacombe D and Verweij J: New response evaluation criteria in solid tumours: revised RECIST guideline (version 1.1). Eur J Cancer 45: 228$247,2009$.

25 Trotti A, Colevas AD, Setser A, Rusch V, Jaques D, Budach V, Langer C, Murphy B, Cumberlin R, Coleman CN and Rubin P: CTCAE v3.0: development of a comprehensive grading system for the adverse effects of cancer treatment. Semin Radiat Oncol 13: 176-181, 2003.

26 Motzer RJ, Bacik J, Murphy BA, Russo P and Mazumdar M: Interferon-alpha as a comparative treatment for clinical trials of new therapies against advanced renal cell carcinoma. J Clin Oncol 20: 289-296, 2002.

27 Ko JJ, Xie W, Kroeger N, Lee JL, Rini BI, Knox JJ, Bjarnason GA, Srinivas S, Pal SK, Yuasa T, Smoragiewicz M, Donskov F,Kanesvaran R, Wood L, Ernst DS, Agarwal N, Vaishampayan UN, Rha SY, Choueiri TK and Heng DY: The International Metastatic Renal Cell Carcinoma Database Consortium model as a prognostic tool in patients with metastatic renal cell carcinoma previously treated with first-line targeted therapy: a population-based study. Lancet Oncol 16: 293-300, 2015.

28 Chrom P, Stec R, Semeniuk-Wojtas A, Bodnar L, Spencer NJ and Szczylik C: Fuhrman grade and neutrophil-to-lymphocyte ratio influence on survival in patients with metastatic renal cell carcinoma treated with first-line tyrosine kinase inhibitors. Clin Genitourin Cancer 14: 457-464, 2016.

29 Hanna N, Sun M, Meyer CP, Nguyen PL, Pal SK, Chang SL, de Velasco G, Trinh QD and Choueiri TK: Survival analyses of patients with metastatic renal cancer treated with targeted therapy with or without cytoreductive nephrectomy: A national cancer data base study. J Clin Oncol 34: 3267-3275, 2016.

30 Petrelli F, Coinu A, Vavassori I, Cabiddu M, Borgonovo K, Ghilardi M, Lonati V and Barni S: Cytoreductive nephrectomy in metastatic renal cell carcinoma treated with targeted therapies: a systematic review with a meta-analysis. Clin Genitourin Cancer 14: 465-472, 2016.

31 Miyake H, Imai S, Tamura K, Sugiyama T, Furuse H, Ozono S and Fujisawa M: Comparison of Tyrosine Kinase Inhibitor Versus Mammalian Target of Rapamycin inhibitor as second-line molecular-targeted therapy for patients with poor-risk metastatic renal cell carcinoma. Anticancer Res 37: 1523-1528, 2017. 
32 Choueiri TK, Escudier B, Powles T, Mainwaring PN, Rini BI, Donskov F, Hammers H, Hutson TE, Lee JL, Peltola K, Roth BJ, Bjarnason GA, Géczi L, Keam B, Maroto P, Heng DY, Schmidinger M, Kantoff PW, Borgman-Hagey A, Hessel C, Scheffold C,Schwab GM, Tannir NM and Motzer RJ: Cabozantinib versus everolimus in advanced renal-cell carcinoma. N Engl J Med 373: 1814-1823, 2015.

33 Zhao Q, Deng X, Hong B, Wang F, Tang X, Yang Y, Gong K, Ye L, Jiang WG and Zhang N: Protein of vascular endothelial growth inhibitor 174 inhibits epithelial-mesenchymal transition in renal cell carcinoma in vivo. Anticancer Res 37: 4269-4275, 2017.

34 Motzer RJ, Escudier B, McDermott DF, George S, Hammers HJ, Srinivas S, Tykodi SS, Sosman JA, Procopio G, Plimack ER, Castellano D, Choueiri TK, Gurney H, Donskov F, Bono P, Wagstaff J, Gauler TC, Ueda T, Tomita Y, Schutz FA,
Kollmannsberger C, Larkin J, Ravaud A, Simon JS, Xu LA, Waxman IM and Sharma P: Nivolumab versus everolimus in advanced renal-cell carcinoma. N Engl J Med 373: 1803-1813, 2015.

35 Kowalczyk AE, Krazinski BE, Godlewski J, Grzegrzolka J, Kiewisz J, Kwiatkowski P, Sliwinska-Jewsiewicka A, Dziegiel $\mathrm{P}$ and Kmiec Z: SATB1 is down-regulated in clear cell renal cell carcinoma and correlates with miR-21-5p overexpression and poor prognosis. Cancer Genomics Proteomics 13: 209-217, 2016.

Received October 1, 2017

Revised November 1, 2017

Accepted November 8, 2017 